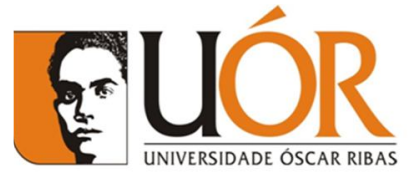

\title{
UNIÓN MONETARIA, FACTIBILIDAD PARA AMÉRICA LATINA
}

\author{
Monetary union, feasibility for latin America / União monetária, factibilidade para \\ América Latina \\ Julio César César Valdés ${ }^{1}$
}

\begin{abstract}
RESUMO
Como resultado de uma série de eventos e acontecimentos que, na ordem económica, tiveram lugar ao longo da história e que incidiram na condução política dos países, é que surge o interesse de muitos continentes, regiões e países de desenhar uma união monetária. O objectivo que se formula, com a presente investigação, refere-se à análise das condições existentes na América Latina, para a possível implementação de uma união monetária. Foram tidas em conta, de acordo com o objectivo definido, as perspectivas de autores com grandes abordagens nos domínios da economia e finanças, entre os quais podem citar-se Bayoumi e Eichengreen (2000), Powell e Sturzenegger (2003), também foram consultados os prémios nobel de economia Joseph Stiglitz (2016) e Robert Mundell (1965). As suas significativas contribuições resultaram de grande aporte para a presente investigação. A metodologia utilizada insere-se na realização de uma análise retrospectiva e transversal da realidade da América Latina para implementar a união monetária. Tanto o objectivo elaborado como a metodologia, incluindo as outras técnicas de investigação utilizadas, permitiram apresentar, como principais resultados, que os países latinoamericanos contam com insuficiência na sua capacidade para obter a quantidade de divisas, suficientes para manter e/ou estabilizar as suas balanças de pagamentos e fechar as suas contas internacionais. Supõe-se que o uso de numerosas moedas cria múltiplas dificuldades para o intercâmbio comercial regional. Portanto, a América Latina ainda não reune as condições necessárias para que haja circulação de uma moeda única, já que os modelos económicos dos diferentes países da região são totalmente divergentes entre sí.
\end{abstract}

Palavras-chave: América Latina, integração, união monetária, exportação.

Recebido: Novembro 2017

Aceitado: Dezembro 2017

\section{RESUMEN}

Como resultado de una serie de eventos y acontecimientos que en el orden económico tuvieron lugar a lo largo de la historia y que incidieron en la conducción

\footnotetext{
${ }^{1}$ Profesor e investigador del Centro de Investigaciones Económicas. Caracas, Venezuela. Correo electrónico: iccesarvaldes@gmail.com
} 
política de los países, es que surge el interés de muchos continentes, regiones y países en diseñar una unión monetaria. El objetivo que se plantea para la presente investigación es analizar las condiciones existentes en América Latina para la posible implementación de una unión monetaria, para el desarrollo del objetivo nos apoyamos en el criterio de autores de relevante trayectoria internacional en las áreas de la economía y las finanzas como fueron Bayoumi y Eichengreen (2000), Powell y Sturzenegger (2003), también fueron consultados los premios nobel de economía Joseph Stiglitz (2016) y Robert Mundell (1965),sus significativos contribuciones resultaron de gran aporte para la presente investigación. La metodología empleada fue la realización de un análisis retrospectivo y transversal de la realidad de América Latina para implementar la unión monetaria. Tanto el objetivo planteado como la metodología, unida a otras técnicas de investigación nos permiten plantear como principales resultados, que los países latinoamericanos cuentan con insuficiencia en su capacidad para obtener la cantidad de divisas suficientes para mantener y/o estabilizar sus balanzas de pagos y cerrar sus cuentas internacionales, se plantea que el uso de numerosas monedas crea múltiples dificultades para el intercambio comercial regional. Se concluye como consideraciones finales que América Latinaaún no reúne las condiciones necesarias para que circule una moneda única ya que los modelos económicos de los diferentes países de la región son totalmente divergentes entre sí.

Palabras claves: América Latina, integración, unión monetaria, exportación

\begin{abstract}
As a result from a series of events and events that took place in the economic order throughout history and that influenced the political conduction of the countries, it is the interest of many continents, regions and countries to design a monetary union. The objective that arises for the present investigation is to analyze the existing conditions in Latin America for the possible implementation of a monetary union, for the development of the objective we rely on the criterion of authors of relevant international trajectory in the areas of economy and finance such as Bayoumi, Eichengreen, nobel prize laureates Joseph Stiglitz and Robert Mundell were also consulted, their significant contributions were a great contribution for the present investigation. The methodology used was the realization of a retrospective and transversal analysis of the reality of Latin America to implement the monetary union. Both the proposed objective and the methodology, together with other research techniques, allow us to state, as main results, that Latin American countries have insufficient capacity to obtain sufficient foreign currency to maintain and / or stabilize their balance of payments and close its international accounts, it is argued that the use of numerous currencies creates multiple difficulties for regional commercial exchange. It is considered as final considerations that Latin America still does not meet the necessary conditions for a single currency to circulate since the economic models of the different countries of the region are totally divergent from each other.
\end{abstract}


Keywords: Latin America, integration, monetary union, export

\section{Introducción}

En la antigüedad las operaciones cambiarias se hacían a manera de trueque mediante diferentes productos, la moneda no se conocía en el concepto moderno en que la tenemos hoy, sino muchos años después. Los aborígenes que habitaron las tierras de América empleaban como medio de pago fundamentalmente los granos de cacao y el oro de las minas americanas, tanto en polvo como en grano.

Con el pasar de los siglos, en el continente latinoamericano y en el resto del mundo se emplearon diversos medios y forma de pago hasta que finalmente surgió la idea de respaldar el oro en papel moneda y así surgió el billete, que ha sido la forma tradicional de pago hasta nuestros días.

El uso de diversas monedas en el mercado internacional ha originado históricamente múltiples problemas para quienes deben llevar a efecto esta actividad (Soberón, 2014).

A mediados del siglo pasado comienza a tomarse en cuenta la importancia que tenía para los países latinoamericanos la definición de un modelo de desarrollo económico y social que fuese complementario con los esquemas políticos basados en la democracia y la justicia social.

Al unísono con estos acontecimientos surgen una serie de eventos de carácter económico que ejercieron una enorme influencia en la conducción política delos países del continente, tales como: el impacto de la industria petrolera, los procesos de industrialización basados en las políticas de sustitución de las importaciones, la consolidación de los sindicatos obreros y campesinos, el desarrollo de proyectos de infraestructura y la llegada de inmigrantes provenientes de diversos países de Europa, Asia y el Caribe.

La presente investigación tiene por objetivo analizar las condiciones existentes en América Latina para la posible implementación de una unión monetaria. La metodología empleada fue la realización de un análisis retrospectivo 
y transversal de la realidad de América Latina para la posible implementación de una moneda única.

\section{Breve análisis teórico de la Unión Monetaria, beneficios y desventajas para América latina}

La Unión Monetaria constituye el acuerdo mediante el cual dos o más países pactan la forma en que compartirán una misma moneda, se da fundamentalmente cuando entre los países firmantes existe un intercambio estable de bienes y servicios y con perspectiva de incrementarse.

Las uniones monetarias también constituyen la manera en que se coordinan las políticas cambiarias más profundas a las que se acogen un grupo de países.

Existen básicamente tres tipos de uniones monetarias (Wikipedia, 2017):

- Informal: basada en la adopción unilateral de una divisa extranjera.

- Formal: basada en la adopción de una divisa extranjeraen virtud de un acuerdo bilateral o multilateral con la autoridad emisora, y en ocasiones apoyada por la emisión de una moneda local bajo un régimen de tipo de cambio fijo.

- Formal con política común: basada en el establecimiento por un número de países de una política monetaria y una autoridad emisora común para su divisa compartida.

Existen diferentes grados de integración regional, que van desde el establecimiento de un Acuerdo Común Preferencial hasta la creación de una Unidad Política, pasando por una Zona de Libre Comercio, Unión Aduanera, Mercado Común, Unión Económica y Unión Monetaria. La mayor parte de los procesos de integración regional afectan las cuestiones comerciales, y son las barreras arancelarias y no arancelarias las que se reducen o eliminan con la finalidad de establecer complementariedades en materia de intercambios comerciales.

De acuerdo con la teoría, una unión monetaria entre países traería varios beneficios: en primer lugar, tener una moneda común eliminaría el sesgo cambiario y esto se vería reflejado en una mejor transparencia de los precios y en menores 
costos de transacción, ya que al tener una moneda común los compradores tendrán una mejor señal de cuánto cuestan los productos en los otros países miembros; segundo, una unión de este tipo permite una mayor integración de los mercados reales y financieros de cada uno de los países integrantes; tercero, de acuerdo con Rose y Stanley (2005), las actividades comerciales entre los países miembros de una unión monetaria aumentarían entre 30\% y 90\%; cuarto, una unión monetaria permite reducir el sesgo inflacionario si este banco central es mucho más gordo que el de una situación de autarquía; y por último, países que han abusado del manejo de una moneda propia como Argentina, Ecuador y Venezuela tendrían beneficios ya que implementar un medio de cambio más estable aumenta la credibilidad de la autoridad monetaria de esos países (García, 2014).

Independientemente a que estos beneficios se logren ver en la realidad objetiva, no constituyen la panacea a los restos que enfrenta hoy el continente latinoamericano, pues la unión monetaria de la misma forma que presenta beneficios también cuenta con desventajas que ejercen gran peso, entre las desventajas más significativas se encuentran: que los países pierden independencia para enfrentar de manera práctica las perturbaciones externas de la economía, pues el banco central no estaría en condiciones de transformar todos sus mecanismos monetarios por el solo hecho de hacerle frente a dicha situación. La unión monetaria podría traer consigo mayor desequilibrio del producto nacional de los países debido a la falta de una autoridad que proceda en consonancia con la articulación económica de cada país. Y por último, se podría dar el caso de que, los países miembros podrían hacer un uso indiscriminado de su gasto público con conocimiento de que finalmente la unión los tiene que salvar necesariamente.

Para el adecuado y correcto análisis del tema en cuestión, realizamos una profunda revisión bibliográfica para conocer el criterio de prestigiosos investigadores, lo que arrojó que los estudios realizados por Bayoumi y Eichengreen (2000) demuestran mediante comparaciones de los ciclos económicos de tratados como el Mercosur que no existe certidumbre que sostenga la creación de una unión monetaria, otros estudios realizados por Powell y Sturzenegger (2003) 
confirman que la integración de los mercados financieros es mejor en Europa que en una posible unión monetaria de Latinoamérica

Otros desatacados intelectuales ha disertado respecto al tema, como fue el profesor estadounidense y premio nobel de economía Joseph Stiglitz (2016) quien considera que no existen condiciones para la implementación de una moneda latinoamericana, sólo sería posible si el continente cumpliera ciertas y determinadas condiciones económicas, políticas y sociales. En cambio otro nobel de economía Robert Mundell (1965) considera factible y sin grandes problemas que se instituya una moneda única latinoamericana. Valoró que existe la suficiente analogía en el continente latinoamericano como para alcanzar el proceso, en vista de que el continente comparte similares idioma, cultura, y hasta el modo de expresión, lo cual ayuda a hacer más fácil la creación de una moneda única.

\section{Realidad económica de América Latina}

Las economías de los países latinoamericanos muestran una gran diversidad en cuanto a lo social, político, cultural, demográfico y económico, y al mismo tiempo inestable por los continuos cambios de enfoques en lo que se refiere a políticas monetarias, lo que ha generado constantes conflictos de distintos índole, tanto internos como externos y con distintos desenlaces a lo largo de la historia del continente.

Independientemente a su larga historia como territorios emancipados, los países de América Latina iniciaron su camino a la industrialización entre 1930 y 1950 mucho antes que los Nuevos Países Industrializados (NPI). Sin embargo sus economías conservan algunos matices del siglo XIX en cuanto a su papel en el comercio internacional, como son: sus exportaciones, aún, están basadas en bienes de origen primario como son: cereales, carnes, frutas tropicales, petróleo y minerales.

El insuficiente dinamismo de las exportaciones ha influenciado en el crecimiento económico general de la región, esto significa que el volumen y el precio de las exportaciones siempre fueron y aún son muy dependientes de los cambios y los precios en la demanda internacional. Las economías 
latinoamericanas se caracterizan por su gran dependencia externa, así como por condiciones internas relacionadas con las políticas de los diferentes gobiernos militares y democráticos que existieron y aún existen en el continente.

En Latinoamérica en general, el mayor desarrollo industrial se inició con motivo de la crisis financiera internacional de 1930, que impulsó una política sustitutiva de importaciones, es decir, el reemplazo de los productos manufacturados de consumo final que tradicionalmente se importaban. Así, la producción industrial respondía a una circunstancia internacional desfavorable. Superados aquellos años de crisis, se creyó que la industrialización debía continuar privilegiando la industria del hierro y el acero, la metalmecánica, la eléctrica y la química, junto con la infraestructura de energía, transporte y telecomunicaciones.

Este desarrollo, se dio a costa de importar maquinarias, tecnología y capital para infraestructura. Como resultado de este desarrollo las exportaciones se diversificaron pero no lo suficiente ya que las importaciones de un conjunto mucho más amplio de productos habían aumentado al unísono. Basta con mirar a nuestro alrededor y analizar la procedencia de algunos productos importados como son: ropa, calzado, galletas, lácteos, golosinas, alimentos envasados, bebidas, autos, heladeras, televisores, computadoras, artículos de plástico, de librería, y demás.

Los antecedentes históricos, teóricos y económicos de los países latinoamericanos demuestran que todos en su conjunto y por separados también han padecido y aún padecen de una enfermedad crónica, denominada insuficiencia en su capacidad para obtener la cantidad de divisas necesarias para mantener $y / 0$ estabilizar sus balanzas de pagos y cerrar sus cuentas internacionales, elementos que son requisito indispensable para llevar acabo una unión monetaria. A ese problema de ausencia o insuficiencia de divisas en los países latinoamericanos se le ha denominado restricción o vulnerabilidad externa, estando este considerado como uno de los principales problemas del subdesarrollo.

Las economías de los países Latinoamericanos requieren aumentar sus niveles de exportaciones a diario, contraer anticipos internacionales o desarrollar 
la inversión extranjera, sea a través de la enajenación de los factores productivos nacionales o de la elevada remuneración de las actividades especulativas, para entonces plantearse una moneda común.

Ante esta problemática, lo más razonable sería acelerar el proceso de integración que a través de pactos regionales viene desarrollándose e incluir dentro de sus objetivos una eventual unión monetaria genuinamente latinoamericana que contribuya a sentar las bases para una ulterior unión política (Soberón, 2009).

\section{Algunas experiencias de uniones monetarias}

Los últimos años han sido testigos de incontables escritos e investigaciones vinculados a los requerimientos previos a las uniones monetarias, las enseñanzas dejadas por estas investigaciones constituyen el incentivo para muchos países que consideran la unión monetaria como una posibilidad real debido al impacto que esta ejerce sobre el comercio.

En el siglo pasado, en distintos momentos y ámbitos geográficos, se trataron de impulsar disimiles proyectos vinculados con este propósito, algunos no perduraron, otros se mantienen con ciertas limitaciones.

Independientemente a las irregularidades que se ponen de manifiesto entre diferentes países y a los diversos grados de desarrollo entre ellos, existen iniciativas de carácter regional que contemplan dentro de su funcionamiento el empleo de una moneda única, analicemos muy brevemente algunas de estas experiencias.

\section{La experiencia europea}

La Unión Europea se alza como el proceso de integración más ambicioso y a la vez exitoso dentro del conjunto de acuerdos regionales existentes en la actualidad. Además se muestra como el ejemplo más fidedigno de cómo llegar a la creación de una moneda única y lo más importante fue que lograron desarrollar los criterios de convergencia que debía cumplir cada para ser admitido en la Unión. 
La Unión Económica y Monetaria que logró formar este bloque regional está integrado por una gran diversidad de países europeos, que comparten no sólo un mercado, sino también el euro como moneda, lo que permite que entre ellos funcione y se desarrolle una política monetaria única.

Con muchos años de anterioridad al continente europeo, América Latina, dio inicio al proceso de integración, sin embargo dicho continente no ha avanzado a la misma velocidad que Europa

\section{La experiencia africana.}

El Franco Centro Africano (CFA) es la moneda oficial de los 14 países que integran la Comunidad Financiera Africana, la mayoría de ellas antiguas colonias francesas(a excepción de Guinea Ecuatorial, que fue colonia española y Guinea-Bissau, colonizada por Portugal).

Según el doctor Francisco Soberón Valdés (2009) exministro-presidente del Banco de Central (BCC) en su libro Finanzas Internacionales y Crisis Global plantea que de la Comunidad Financiera Africana, seis países del continente africano (Camerún, República Centroafricana, República del Congo, Gabón, Guinea Ecuatorial y Chad) emplean el Franco CFA de África Central, el que está fijado al euro y cuenta con respaldo del Banco de los Estados de África Central con sede en Camerún. Estos países a la vez están integrados en una unión nombrada Comunidad Económica y Monetaria de África Central (CEMAC) la que surgió con el objetivo de establecer un estrecho vínculo de cooperación entre los países miembros, adoptar iniciativas nacionales que permitan eliminar los obstáculos que con frecuencia se originan en el comercio entre esas naciones y la promoción y desarrollo de esquemas de desarrollo y conjunción de proyectos industriales.

Al unísono, otras ocho naciones de este mismo continente (Benín, Burkina Faso, Costa de Marfil, Malí, Níger, Senegal, Togo y Guinea Bissau) efectúan sus operaciones en francos CFA del África Occidental, moneda que de igual forma está fijada con relación al euro con idéntico tipo de cambio que el Franco de África Central (CFA) y que a la vez son emitidos por el Banco Central de los Países de 
África Occidental que cuenta con su sede en Senegal. Este acuerdo también conocido como Unión Económica y Monetaria de África Occidental, tiene como misión fundamental fortalecer la capacidad económica y financiera de las naciones miembros, mediante el desarrollo de proyectos y la mutua cooperación.

\section{La experiencia Centroamericana.}

En 1961 se creó la Cámara de Compensación Centroamericana con la participación de los bancos centrales de Guatemala, El Salvador y Honduras a la que se agregó el Banco Central de Nicaragua en 1962 y el Banco Central de Costa Rica en 1963. Según informe presentado en el mes de Enero de 2009 por la Secretaría Permanente del Sistema Económico Latinoamericano y del Caribe (SELA, 2009) con sede en Caracas, Venezuela, para conformar este mecanismo multilateral de compensación, cada banco central aportó un monto del cual del 25 por ciento de sus reservas, aporte que fue realizado en dólares para la creación del Fondo de Garantías destinado a liquidar los saldos a los bancos que al momento del corte resultaran acreedores y el restante 75 por ciento era un aporte en moneda nacional de los países miembros para el Fondo de Operaciones Corrientes, que era el instrumento central de la Cámara.

En el momento en que el SELA como organismo económico regional, estudió y analizó en el año 2009 los Propósitos, antecedentes y condiciones necesarias para que avanzará el Sistema de Compensación Regional (SUCRE) en la región reveló que ya desde el año 1964 se había firmado un Acuerdo para crear la Unión Monetaria Centroamericana, que en su artículo primero establecía como objetivo fundamental promover la coordinación y armonización de las políticas monetarias, cambiarias y crediticias de los países centroamericanos, y se conformó el Consejo Monetario Centroamericano.

El estudio analizó también como La Cámara de Compensación Centroamericana procedió a crear su propia unidad de cuenta para el registro de las operaciones y esta moneda de carácter contable se denominó peso centroamericano (\$CA) con una paridad equivalente a un dólar de los Estados Unidos, a su vez la paridad del peso centroamericano con las otras monedas de 
los países miembros de la Cámara era de 1.00 quetzales de Guatemala; 2.00 lempiras de Honduras; 2.50 colones salvadoreños; 6.625 colones costarricenses y 7.00 córdobas de Nicaragua.

Desde su creación y hasta el año de 1980, el mecanismo de Compensación de Pagos Centroamericano fue mostrando una mayor capacidad para liquidar las operaciones compensadas sin utilizar dólares, atendiendo solo a la liquidación mediante débitos y créditos en las cuentas de los países miembros. Así, se redujo sustancialmente la necesidad de recurrir a divisas para realizar los pagos entre las naciones que participaban en el acuerdo regional de compensación, y a partir de la segunda mitad de la década de los setenta se empleaba la divisa en menos del 10 por ciento del comercio intracentroamericano.

La violenta crisis que vivió la región a principios de los años ochenta, y que se expresó en una fuerte contracción económica, en la reducción de los montos de comercio y en una aguda falta de divisas, impactó severamente en el mecanismo de compensación de pagos, de manera que las operaciones cursadas a través de la cámara comenzaron a disminuir significativamente en un escenario de drásticas modificaciones en la política cambiaria de los países del área.

La acumulación de saldos deudores condujo a la ineficacia de la Cámara de Compensación, pues los países establecieron convenios y líneas de crédito bilaterales con distintas modalidades de pago, en un escenario generalizado de endeudamiento que les impedía hacer frente a los compromisos externos.

En 1993 y a consecuencia de las dificultades existentes para el pago de las deudas entre los bancos centrales de los países miembros, se decidió el cierre de este mecanismo de compensación regional, con un saldo final favorable si se tiene presente que permitió conseguir liquidez adicional a través de la utilización de una unidad de cuenta que fue una sustituta eficiente de divisas, como lo demostró el efectivo trabajo de la Cámara de Compensación en sus tres décadas de funcionamiento. 


\section{El mecanismo de compensación de pagos entre Argentina y Brasil.}

El Sistema de Pagos en Monedas Locales (SML) comenzó a funcionar el 6 de octubre de 2008 y con ello se hizo posible que las transacciones financieras entre ambos bancos centrales y demás bancos participantes del SML, y a la vez de estos con los exportadores e importadores, esto permitió que se concretaran las respectivas monedas locales, para proceder ya sea a pagar las importaciones o a cobrar las exportaciones.

EI SML, en tanto sistema de compensación y transferencia de valores, no fue creado con fines de lucro para los bancos centrales para evitar que se realizaran operaciones de cambio peso-dólar-real para los importadores argentinos y real-dólar-peso para los importadores brasileños, con lo que simplificaban los procedimientos en comparación con las transacciones realizadas en dólares, se reducen los costos financieros y administrativos de las transacciones y se apoya la desdolarización del sistema financiero del MERCOSUR, en un contexto de fuerte desestabilización y reajuste del sistema financiero a nivel mundial.

Si bien resulta temprano para poder hacer un balance del funcionamiento del Sistema de Pagos en Moneda Local Argentino-Brasileño, es importante tener presente que dicho mecanismo puede constituirse en un primer paso en dirección al establecimiento de una integración monetaria regional, según ha sido planteado por autoridades de la secretaria permanente de ambos países.

\section{Asociación Latinoamericana de Integración (ALADI)}

En nuestro continente funciona actualmente el llamado Convenio de Pagos y Créditos Recíprocos dentro del marco de la ALADI, suscrito en 1982 y al cual pertenecen 12 países (Argentina, Bolivia, Brasil, Colombia, Chile, Ecuador, México, Paraguay, Perú, República Dominicana, Uruguay y Venezuela), y cuenta con un mecanismo de compensación multilateral y un sistema de garantías.

El Banco Central de la Reserva de Perú actúa como agente del sistema y a la vez es el encargado de efectuar las compensaciones multilaterales, pero la reserva Federal de Nueva York es el corresponsal común a través del cual se 
liquidan los saldos acreedores y deudores, lo que refuerza el papel hegemónico de la moneda de Estados Unidos en la región; de manera que no podría aseverarse que este es un mecanismo que coadyuve a una integración netamente latinoamericana.

Esta limitante da muestra del progresivo decaimiento del sistema, y más de treinta años de su creación, el volumen de exportaciones cuyo pago se liquida a través de sus mecanismos, no alcanza siquiera el 10 por ciento del total de la región.

En la década de los noventas y principios de este siglo, Estados Unidos ejerció grandes presiones para imponer el dólar como moneda única de la región, aunque este propósito no siempre fue expresado abiertamente, debido al rechazo que incita por sus evidentes designios hegemónicos claramente contrarios a los intereses nacionales de los pueblos de la región.

Para llevar a cabo esta estrategia, Estados Unidos contó con el decidido apoyo de algunos gobiernos de la región, siendo esto parte integrante del proyecto norteamericano de la Alianza de Libre Comercio para las Américas (ALCA) que finalmente fracasó, al no quedar aprobado por los jefes de estado y de gobiernos de la región, en el año 2005 en Mar del Plata, Argentina.

No obstante el dólar tiene una fuerte presencia en la región, Panamá y Ecuador son dos países latinoamericanos donde la moneda que circula es el dólar con todas las atribuciones correspondientes a un signo monetario nacional, en muchos países una gran parte de los depósitos bancarios están constituidos en dólares. Algunos gobiernos latinoamericanos emiten deuda pública denominada en esa moneda y en varios países, como Venezuela, los bienes de mayor valor como las casas y los automóviles, por solo citar dos ejemplos, se cotizan y venden en dólares.

Este pequeño repaso por solo algunas de las experiencias que funcionan hoy en el mundo, demuestran que en lo que llevamos de nuevo siglo, los avances más significativos de integración regional han tenido lugar más a nivel político que a nivel de los acuerdos comerciales subregionales. Por la idiosincrasia latinoamericana, los regímenes políticos y las relaciones entre ellos tienen un 
marcado carácter presidencialista, donde la personalidad de los líderes, sus empatías y sus inclinaciones políticas determinan de forma fundamental el rumbo que los procesos de integración toman (Purroy, 2013).

\section{Problemas de la diversidad monetaria}

El panorama mundial en la actualidad se complejiza mucho más, pues el volumen de exportaciones a nivel mundial supera los diez millones de millones de dólares y existen alrededor de 200 naciones, de las cuales la inmensa mayoría emite su propia moneda.

Agréguese que a partir de 1971, el gobierno de los Estados Unidos le retiró el respaldo en oro al dólar, poniendo fin a la era de paridades fijas que prevaleció desde 1944 bajo el sistema del patrón dólar-oro, y abriendo el paso a una nueva fase de tipos de cambios flotante.

Con la llegada de la era de la globalización, la posibilidad que ofrece la interconexión electrónica en tiempo real entre países de distintos usos horarios, y la cotización del valor de las monedas que fluctúa entre sí por segundo, son elementos que propician la actividad especulativa a gran escala en estos mercados y que puede originar en pocas horas, incluso en minutos, grandes variaciones en los tipos de cambios, hechos estos que se dan en las regiones que cuentan con una moneda única.

En América Latina existen múltiples divisas: nacionales y extranjeras, estas deben cumplir tres funciones fundamentales: ser unidad de cuenta que permita medir el valor de los bienes y servicios y de los activos financieros; ser un medio de pago utilizado para realizar las transacciones comerciales sin tener que recurrir al trueque, y por último, constituir un depósito de valor en el sentido en que facilita la realización de operaciones diferidas en el tiempo (Khoudour-Casteras, 1999).

El uso de numerosas monedas crea graves dificultades en el intercambio comercial entre países, un ejemplo fidedigno que corrobora este planteamiento lo tenemos cuando un fabricante tiene pagar en su moneda local la fuerza de trabajo y una parte de los insumos que requiere para producir sus mercancías, no resultaría extraño que también tuviera que adquirir directamente en el extranjero 
varias de las materias primas que necesita, para lo cual tendría que analizar cotizaciones expresadas en distintas monedas, llevándolas a una unidad de cuenta común a fin de hacerlas comparables. Si finalmente realiza la importación, casi seguramente deberá pagar en la moneda del país exportador. Esto lo involucra necesariamente en una transacción de compra de divisas a través de su banco, en un mercado en el que los tipos de cambio fluctúan continuamente.

Algo parecido sucedería si sus productos son destinados a la exportación, pues se verá precisado a confrontar constantemente sus precios con los artículos similares fabricados en otros países, a los efectos de garantizar su competitividad respecto a estos últimos, incluso aun cuando la producción sea para el mercado local, tendrá también que estar muy al tanto de los precios de la competencia internacional, cotizados en monedas distintas a la de su país, en un mundo globalizado donde se han creado las condiciones para que las grandes transnacionales puedan acceder a los mercados de cualquier país, sin ninguna barrera que proteja a los menos desfavorecidos.

Siguiendo la línea de pensamiento del nivel de actuación de este comerciante, el bien se podría ahorrar estos problemas si el desempeño de su actividad productiva la realizara en un país donde funcionara una moneda única y sus exportaciones las hiciera a países donde funciona la misma moneda del país productor, por lo que para el resultaría bastante complejo tener que estar realizando constantemente cálculos relacionados con los tipos de cambio de distintas monedas que, como ya dijimos, fluctúan continuamente.

Este dilema se hace más escalabroso cuando los productores y comerciantes tienen que acudir con frecuencia a los mercados externos, para obtener créditos con vistas a financiar sus actividades. En estos casos tienen que tomar préstamos en monedas distintas a las suyas y a tasas de interés que son también flotantes y diferentes según la moneda que se trate, en países o regiones que cuentan con una moneda en común los niveles de producción y de exportación se mantienen relativamente estables y se ahorran el trabajo de evaluar el comportamiento de otras monedas distinta a la suya 
Toda esta situación se traduce en incertidumbre y riesgo de pérdidas financieras adicionales que debe asumirse en la esfera de la producción y la circulación, ante todas estas dificultades, países con grandes flujos comerciales entre sí; cercanos geográficamente, o con afinidad política intentaron crear en el pasado distintas integraciones regionales (algunas con éxito y otras no) con el fin de promover, simplificar y abaratar su intercambio comercial.

\section{Unión Monetaria en América Latina, ventajas y riesgos}

A raíz de las condiciones que en la actualidad prevalecen en las finanzas internacionales y del proceso de globalización que hoy se ponen de manifiesto en nuestro planeta, se impone de manera inminente que América Latina reflexione profundamente y de manera muy cuidadosa en cuanto a una unión monetaria futura. El doctor Mauricio Reina (2010) ex viceministro de Comercio Exterior de Colombia en su programa de radio Cuestión de Plata del 06 de Mayo del 2010 analizó los detalles de la reunión del Foro Económico Mundial celebrado en Cartagena de Indias, Colombia en el 2010, quien desde una perspectiva integracionista planteó que dicho conclave dejó sobre la mesa muchas ideas para meditar, tal vez la más polémicas de todas haya sido la que consiste en la posibilidad de que América Latina trabaje para tener una moneda única en un plazo de 10 años,(Reina, 2014) esta idea puede llegar a nuestras mentes como una manera de hacernos reflexionar, porque siendo países, mayoritariamente, fronterizos deberían conformar un espacio económico único y hasta con una moneda en común, sin embargo esta idea tiene muchos más inconvenientes que los beneficios que podría ocasionar.

La instauración de una moneda común para Latinoamérica sin dudas que tendrías beneficios, pero también tendría que enfrentar riesgos, el beneficio primordial se daría si la mayor parte del comercio de los países latinoamericanos se da entre ellos mismos, lo que provocaría la reducción de costos en el momento 
de cambiar de una moneda a otra y se minimizan los riesgos de que haya una devaluación en algunos de ellos.

Esa moneda común debe ser poseedora de un valor estable volátil, debido a que la inestabilidad política y económica dominante en América Latina ha provocado una tradición retorcida de sus monedas, por lo que la nueva moneda debiera nacer con una elevado respaldo para lograr posesionarse de forma adecuada en el comercio internacional, respaldo que debiera estar dado por un elevado aporte de los bancos centrales de cada país y cabría preguntarnos ¿Están en condiciones los bancos centrales de cada país latinoamericano de desembolsar elevadas cantidades monetarias, para que desde que esta moneda surja sea fuerte y sólida? Tal vez si, tal vez no.

En América Latina, el análisis monetario comprendería las finalidades que tiene una moneda internacional, convergencias de la política económica y fiscal, integración económica, la pérdida de la soberanía monetaria (Llinás, 2011).

Estos son elementos, que unidos a la falta de una combinación fiscal y monetaria acorde entre países, nos llevan a la reflexionar que América Latina no está en condiciones objetivas para integrarse al Sistema Monetario Internacional con una moneda única.

Pero para hacer un análisis correcto del tema debemos tener en cuenta una variable no menos importante y es el mercado de oportunidades y comercio entre los países latinoamericanos, el que en su mayoría se da entre ellos mismos lo que sería beneficioso para muchos países pero menos atractivos para las economías de otros, como es el caso de Colombia que menos de la mitad de su comercio se da con países latinoamericanos, lo que hace que se maximice el riesgo.

Otro gran peligro de los se podrían poner de manifiesto, es que países con un gran desarrollo como Brasil tenga que compartir la misma moneda con países con menor grado de desarrollo como Uruguay, o que países con diferentes políticas económicas como Venezuela y Argentina tengan que asumir la misma moneda en común. Si esto llegara a cumplirse, las economías con mayor desarrollo comenzarían a preocuparse por las de menos desarrollo en cuanto a 
déficit fiscal, niveles de endeudamiento y la pérdida de confianza de los inversionistas y al tener estos países una moneda en común con otras economías se comenzaría a perder también la confianza en esa moneda, elementos que desde una perspectiva analítica deja en claro que cuando unos países asumen una moneda común están asumiendo la responsabilidad solidaria de lo que están haciendo los demás con sus propias finanzas.

La realidad es que una unión monetaria Latinoamericana exige fuertes condiciones previas de partidas en los distintos países para que pueda funcionar, hablamos por lo tanto de una necesidad de integración financiera, económica, bancaria y comercial entre los distintos países, como ya vimos en América Latina hay procesos de integración monetarias en marcha, pero son más nominales que reales y la verdad es que las condiciones de partidas no se cumplen (Fernández, 2011) o se cumplen parcialmente.

Para el logro de Unión Monetaria Latinoamericana, cada país interesado en participar en dicha unión debiera alcanzar y respetar una serie de estándar, como son: déficit fiscal, deuda pública, tasa de inflación, tasa de interés, respeto a los márgenes de fluctuación, sin embargo no existe en el continente latinoamericano un nivel de estandarización que respalde una unión regional. Estos elementos se imponen como condición previa para la necesaria e importante integración financiera y bancaria ya que se formula como punto cardinal a partir del cual los capitales fluyan libremente entre los distintos países

Las economías de los países que conformen la Unión Monetaria deben tener una balanza de capitales abierta y lo que es más importante, que tengan sistemas financieros y bancarios integrados, que los bancos operen en la región y sirvan para canalizar el flujo de ahorro de inversión entre los distintos países sin sesgos nacionales y domésticos y para ello es muy importante una integración de los sistemas de supervisión y regulación bancaria, una armonización de la legislación bancaria en América Latina y eso está muy lejos de suceder en el continente latinoamericano.

A la vez dicha unión exige un alto grado de integración comercial entre los distintos países que formaran dicha unión y sin embargo la mayor parte de los 
países de América Latina tiene como su principal socio comercial a Estados Unidos y China y no existe un comercio suficientemente perecedero entre países del continente latinoamericanos.

Todos los elementos valorados hasta aquí demuestran que en los momentos actuales América Latina no cumple los requisitos básicos para plantearse una unión monetaria.

\section{Conclusiones}

Desde la creación de la Unión Monetaria Europea las diferentes uniones monetarias se han sentido significativamente atraídas, aunque la práctica demuestra que las uniones monetarias no están de modas, las experiencias económicas que se nos muestran hoy no son muy edificante y la verdad es que los países europeos todavía tienen serias dificultades para recuperarse de la crisis económica y financiera y eso tiene mucho que ver con el proceso de unión monetaria que se lleva a cabo en el continente Latinoamericano, reconozco cómo economistas y financistas que Europa está al borde del colapso total.

Por muchos años se ha hablado, se han diseñado monedas y se han escrito documentos de las posibilidades reales de una unión monetaria en América Latina, pero desafortunadamente ninguna idea se concretó y mucho menos se llevó a vía de hecho y es porque los intereses económicos, políticos y sociales de sus países aunque parecidos continúan siendo diferentes en muchos ordenes, inicialmente se debieran confrontar una serie de estándares comerciales que aún están muy lejos de ser parecidos, dado la diversidad de las relaciones económicas internacional.

No es buena idea que en las circunstancias actuales en que se desarrolla la economía de América Latina implementar una moneda única ya que los modelos económicos que tenemos hoy en día en la región son totalmente divergentes. 


\section{Referencias Bibliográficas}

Bayoumi, Tamim y Eichengreen, Barry. (2000). Sobre los arreglos monetarios regionales para la ASEAN. Revista Internacional de Economía Japonesa, vol. 14, Nro. 2, Tokio, Japón, (Pp.121-148).

Fernández, Fernando. (2011). El fin de las Uniones Monetarias. El Mundo. Extraído de www.youtube.com/watch?v=Y1toyyh9tSo. Consulta: 14/03/2016

García, Diego. (2014). Unión Monetaria: ¿Recomendación para Latinoamérica? El espectador. Extraído de www.blogs.elespectador.com/economia/el-maleconomista/union-monetaria-recomendacion-para-latinoamerica. Consulta: $17 / 11 / 2016$

Khoudour-Casteras, David. (1999) ¿Una moneda única para América Latina? (primera edición). Editorial Universidad Externado de Colombia. Colombia.

Llinás, Fernando. (2011). América latina: ¿Una moneda única? Redacción portafolio. Extraído de www.portafolio.co/opinion/redaccionportafolio/america-latina-moneda-unica-130036. Consulta: 05/04/2016

Mundell. Robert. (1965). El sistema monetario internacional; Conflicto y reforma, (primera edición), editorial Comité de Comercio Canadiense. Canadá.

Powell, Andrew y Sturzenegger, Federico. (2003). Dolarización: el vínculo entre la devaluación y el riesgo de incumplimiento, (primera edición) editorial MIT Press. Estados Unidos.

Purroy, Miguel. (2013)¿Moneda común o propia?(primera edición) Editorial Melvin. Venezuela.

Reina, Mauricio. (2010).Una moneda única para América Latina. Extraído de www.youtube.com/watch?v=od3-jBpEPdo. Consulta: 06/10/2016

Soberón. Francisco.(2009). Finanzas Internacionales y Crisis Global. (primera edición) Instituto Cubano del Libro. Editorial José Martí. Cuba.

Soberón. Francisco. (2014). EURO: Unión Monetaria y Crisis. (segunda edición) Instituto Cubano del Libro. Editorial de Ciencias Sociales. Cuba.

Stiglitz, Joseph. (2016). El euro: cómo una moneda común amenaza el futuro de Europa (primera edición). Editorial Norton Company. Estados Unidos.

Wikipedia. Enciclopedia libre. (2017). Monetaria es. Extraído de www.es.wikipedia.org/wiki/Union monetaria. Consulta: 15/07/2016 